\title{
Ureaplasmas and mycoplasmas in chimpanzees of various breeding capacities
}

\author{
D. Taylor-Robinson*, M. F. Barile†, P. M. Furr*, and C. E. Graham $\ddagger$ \\ ${ }^{*}$ Division of Sexually Transmitted Diseases, Clinical Research Centre, Harrow, Middlesex, U.K.; \\ $\lceil$ †ycoplasma Laboratory, Center for Drugs and Biologics, Bethesda, Maryland 20205, U.S.A.; and \\ $\ddagger$ Primate Research Institute, Holloman Air Force Base, New Mexico 88330, U.S.A.
}

\begin{abstract}
Summary. Adult chimpanzees ( 24 male, 76 female) with low and high rates of conception were examined for ureaplasmas, arginine-metabolizing mycoplasmas and chlamydiae. Ureaplasmas were isolated from the throat of only 1 male and 1 female animal, but from the urethra of $29 \%$ of the males and from the vagina of $95 \%$ of the females. Mycoplasmas were isolated from the throat more often than were ureaplasmas, but from the genital tract with about the same frequency as ureaplasmas. The numbers of organisms, of either type, isolated from the vagina were larger than the numbers isolated from the male urethra. Chlamydiae were not isolated from any animal. The occurrence of ureaplasmas and mycoplasmas and the numbers of these organisms isolated were similar in animals with low or high rates of conception. Furthermore, no association was noted between the organisms in the lower genital tract and the occurrence of abortion and/or stillbirth.
\end{abstract}

\section{Introduction}

Ureaplasmas, unique among organisms of the order Mycoplasmatales in metabolizing urea, have been found in a variety of animal species (Taylor-Robinson \& Gourlay, 1984). Ureaplasmas of human origin have been ascribed to the species Ureaplasma urealyticum and have been associated with infertility, spontaneous abortion, stillbirth and infants of low birth weight (Taylor-Robinson \& McCormack, 1980), although there is no proof of a causal relationship. Brown et al. (1976) were the first to isolate ureaplasmas from the throat and genital tract of chimpanzees. Swenson \& O'Leary (1977) recovered them from $8(35 \%)$ of 23 female chimpanzees and noted that the animals had a high rate of reproductive failure, whereas Khatamee (1982) noted that $8(36 \%)$ of 22 chimpanzees he examined not only were ureaplasma-positive but also were breeders. Because the relationship between infection by ureaplasmas and reproductive failure has not been established in these animals or man we have studied the problem further by examining a colony of chimpanzees whose reproductive ability was known. Ureaplasmas, in addition to mycoplasmas and Chlamydia species, were sought, chlamydiae also having been associated with human reproductive problems (Mårdh, 1986).

\section{Materials and Methods}

Chimpanzees. Adult male and female chimpanzees in a closed breeding colony at the Primate Research Institute were examined. Female animals were housed in pairs until one was deemed suitable for mating, at which time it was caged with a proven fertile male. Information on conceptions, normal births, abortions and stillbirths was available for each animal, together with the number of reproductive cycles from 1979 to 1982, during which time the same breeding system was maintained. 
Sampling procedures. The animals were anaesthetized with ketamine hydrochloride $(10 \mathrm{mg} / \mathrm{kg}$ body weight $)$ given intramuscularly. Plain cottonwool swabs on plastic sticks were used to take specimens from the throat and deep vagina of all animals. Swabs (Calgiswabs type 1; Inolex, IL, U.S.A.) were inserted 3-5 cm into the male urethra. Each swab was rinsed and its contents expressed in $1.0 \mathrm{ml}$ of transport medium. The swab was discarded and the medium was snap frozen in an alcohol-solid $\mathrm{CO}_{2}$ mixture and transported to the laboratory where it was stored at $-70^{\circ} \mathrm{C}$ until tested; this occurred within 2 months of storage. One swab was obtained from the throat of each animal, and was expressed into transport medium for ureaplasmas and mycoplasmas (see below). Two swabs were obtained from the genital tract, the first being expressed into transport medium for ureaplasmas and mycoplasmas and the second into transport medium for chlamydiae.

Media and culture techniques. Urea-containing medium for the isolation and growth of ureaplasmas and argininecontaining medium for arginine-metabolizing mycoplasmas were used and have been described previously (Manchee \& Taylor-Robinson, 1968; Taylor-Robinson et al., 1971). The transport medium comprised the same components as the growth medium but without the urea or arginine substrates. Transport medium in which a swab had been expressed was diluted in the growth medium in a series of 10 -fold steps $(0.2 \mathrm{ml}$ to $1.8 \mathrm{ml})$ up to a dilution of $10^{-8}$. The highest dilution at which a colour change occurred after incubation at $37^{\circ} \mathrm{C}$ was considered to contain one colourchanging unit (c.c.u.) (Taylor-Robinson \& Purcell, 1966). Some arginine-metabolizing isolates were identified as Mycoplasma hominis with specific rabbit antiserum in agar disc growth-inhibition tests (Clyde, 1964). Sucrosephosphate medium containing $10 \%$ heat-inactivated fetal calf serum (2SP; the transport medium for chlamydiae) was inoculated into cycloheximide-treated McCoy cell cultures, as described previously (Thomas et al., 1977), and chlamydial inclusions were sought.

\section{Results}

\section{Occurrence of micro-organisms in the throat and genital tract}

Ureaplasmas, as shown in Table 1, were isolated rarely from the throat of male or female chimpanzees. In contrast, the organisms were isolated from the urethra of almost one-third of male animals and from the vagina of nearly all female animals. Furthermore, the number of ureaplasmas in vaginal specimens was greater than in urethral specimens.

Arginine-metabolizing mycoplasmas were isolated from the throat more often than were ureaplasmas (Table 1) but from the genital tract with about the same frequency as ureaplasmas, the mycoplasmas being isolated again more frequently and in larger numbers from female than from male animals. The difference in recovery of organisms from male and female animals was emphasized by the fact that ureaplasmas and mycoplasmas together were isolated from the urethra of only 3 of the 24 male animals but from the vagina of 68 of the 76 females.

Chlamydiae were not isolated from the genital tract of any of the animals and were not sought in the throat.

Table 1. Distribution of ureaplasmas and arginine-metabolizing mycoplasmas in male and female chimpanzees

\begin{tabular}{|c|c|c|c|c|c|}
\hline \multirow{2}{*}{$\begin{array}{l}\begin{array}{l}\text { Micro- } \\
\text { organism }\end{array} \\
\text { Ureaplasma }\end{array}$} & \multirow{2}{*}{$\frac{\text { Sex }}{\text { Male }}$} & \multirow{2}{*}{$\begin{array}{l}\begin{array}{l}\text { Site } \\
\text { tested }\end{array} \\
\text { Throat } \\
\text { Urethra }\end{array}$} & \multicolumn{2}{|c|}{$\begin{array}{c}\text { No. of animals } \\
\text { positive/no. tested }(\%)\end{array}$} & $\begin{array}{c}\begin{array}{c}\text { Geometric } \\
\text { mean titre }\end{array} \\
10^{1}\end{array}$ \\
\hline & & & $\begin{array}{r}1 / 24 \\
7 / 24 \\
1 / 76 \\
72 / 76\end{array}$ & $\begin{array}{c}(4) \\
(29) \\
(1 \cdot 3) \\
(95)\end{array}$ & $\begin{array}{l}10^{1} \\
10^{2 \cdot 1} \\
10^{1} \\
10^{3 \cdot 2}\end{array}$ \\
\hline Mycoplasma & $\begin{array}{l}\text { Male } \\
\text { Female }\end{array}$ & $\begin{array}{l}\text { Throat } \\
\text { Urethra } \\
\text { Throat } \\
\text { Vagina }\end{array}$ & $\begin{array}{r}3 / 24 \\
8 / 24 \\
16 / 76 \\
70 / 76\end{array}$ & $\begin{array}{l}(13) \\
(33) \\
(34) \\
(92)\end{array}$ & $\begin{array}{l}10^{1} \\
10^{1} \\
10^{1 \cdot 7} \\
10^{4 \cdot 9}\end{array}$ \\
\hline
\end{tabular}




\section{Relation between micro-organisms and conception}

As the isolation of ureaplasmas and mycoplasmas from the lower genital tract of almost all female animals indicated that it would not be possible to relate the mere presence of the organisms to difficulties in conception, quantitative assessments were made. However, as shown in Table 2, the numbers of either micro-organism, in terms of geometric mean titre, in genital specimens from animals with low and high conception rates were similar. Furthermore, the frequency with which either micro-organism was isolated in large numbers was also similar in animals with low and high rates of conception.

Table 2. Relation between conception rate and ureaplasmas and arginine-metabolizing mycoplasmas in the lower genital tract of chimpanzees

\begin{tabular}{|c|c|c|c|c|c|}
\hline \multirow[b]{2}{*}{$\begin{array}{l}\text { Conception } \\
(\%)^{*}\end{array}$} & \multirow[b]{2}{*}{$\begin{array}{l}\text { No. of } \\
\text { animals }\end{array}$} & \multicolumn{2}{|c|}{ Ureaplasmas } & \multicolumn{2}{|c|}{ Mycoplasmas } \\
\hline & & $\begin{array}{c}\text { Geometric mean } \\
\text { titre } \nmid \text { (c.c.u. } \ddagger \text { ) }\end{array}$ & $\begin{array}{c}\text { No. }(\%) \text { of animals } \\
\text { with titre of } \\
10^{4}-10^{6} \text { c.c.u. } \ddagger\end{array}$ & $\begin{array}{c}\text { Geometric mean } \\
\text { titre† (c.c.u. } \downarrow)\end{array}$ & $\begin{array}{c}\text { No. }(\%) \text { of animals } \\
\text { with titre of } \\
10^{5}-10^{7} \text { c.c.u. } \ddagger\end{array}$ \\
\hline $0-10$ & 22 & $10^{3 \cdot 3}$ & $10(45)$ & $10^{5 \cdot 3}$ & $17(77)$ \\
\hline $1 \mathrm{I}-30$ & 19 & $10^{3 \cdot 0}$ & $7(37)$ & $10^{4 \cdot 2}$ & $12(63)$ \\
\hline $3 !-50$ & 20 & $10^{2 \cdot 8}$ & $6(30)$ & $10^{4 \cdot 3}$ & $11(55)$ \\
\hline $5 I-100$ & 14 & $10^{2 \cdot 9}$ & $5(36)$ & $10^{4 \cdot 7}$ & $10(71)$ \\
\hline
\end{tabular}

*Proportion (\%) of cycles with a proven male which resulted in conception between 1979 and 1982 inclusive. †For all the animals in the group.

łc.c.u. $=$ colour-changing unit (see 'Materials and Methods').

Table 3. Relation between abortion/stillbirth and ureaplasmas and argininemetabolizing mycoplasmas in the lower genital tract of chimpanzees

\begin{tabular}{|c|c|c|c|c|c|}
\hline \multirow{3}{*}{$\begin{array}{l}\text { No. of } \\
\text { animals }\end{array}$} & \multirow{3}{*}{$\begin{array}{l}\text { Proportion (range) of } 6 \\
\text { or more conceptions ending } \\
\text { in abortion/stillbirth }\end{array}$} & \multicolumn{4}{|c|}{ Animals infected by } \\
\hline & & \multicolumn{2}{|c|}{ Ureaplasmas } & \multicolumn{2}{|c|}{ Mycoplasmas } \\
\hline & & No. & $\mathrm{GMT}^{*}$ & No. & $\mathrm{GMT}^{*}$ \\
\hline 14 & $<15 \% \quad(0-14 \%)$ & 13 & $10^{3 \cdot 2}$ & 13 & $10^{4 \cdot 4}$ \\
\hline 10 & $\geqslant 30 \%(30-86 \%)$ & 8 & $10^{2 \cdot 8}$ & 7 & $10^{4 \cdot 4}$ \\
\hline
\end{tabular}

*Geometric mean titre (c.c.u.).

\section{Relation between micro-organisms and abortion/stillbirth}

The occurrence and numbers of micro-organisms in the genital tract of 14 chimpanzees having the best outcome of conception, i.e. a normal pregnancy or infrequent abortion/stillbirth, were compared with those in 10 chimpanzees having the worse outcome, i.e. $30 \%$ or more of the conceptions of each animal ending in failure. As shown in Table 3, ureaplasmas and mycoplasmas were not found more frequently or in larger numbers in the latter group. 


\section{Discussion}

We have not identified the arginine-metabolizing mycoplasmas occurring in the throat of the chimpanzees but suspect from previous observations (Cole et al., 1970) that many of them are Mycoplasma salivarium. All of those from the genital tract that were identified proved to be $M$. hominis. We isolated ureaplasmas from a much larger proportion of chimpanzees than have other investigators (Swenson \& O'Leary, 1977; Khatamee, 1982). This may be due to differences in the animal colonies or to the use of more sensitive isolation procedures or both. The extent to which the ureaplasmas isolated from the chimpanzees that we or others have examined are similar to those of human origin has not been explored, although one strain isolated from another chimpanzee source had a polyacrylamide gel protein profile similar to that of human strains (Mouches et al., 1981). Certainly, the anatomical distribution of the chimpanzee ureaplasmas and mycoplasmas was similar to that seen in humans, i.e. infrequent occurrence in the throat compared to that in the genital tract and a greater frequency in the female than in the male genital tract (Taylor-Robinson, 1986; Furr \& Taylor-Robinson, 1987). This is quite different from that in marmosets in which ureaplasmas are found predominantly in the throat (Furr et al., 1976). The occurrence of ureaplasmas and mycoplasmas in the genital tract of only about one-third of male chimpanzees in contrast to nearly all females suggests that infection of the male urethra is more difficult to achieve. However, irrespective of infection, male chimpanzees accomplished successful matings. Whether or not ureaplasmas produce inflammatory changes in the male urethra, similar to non-gonococcal urethritis in man, is a moot point. Such changes were not sought but seem unlikely in view of the small numbers of organisms recovered and the likelihood of long-standing colonization. The possibility that primary infection might cause disease is worth exploring.

Conclusions about the involvement of chlamydiae in reproductive failure in chimpanzees could not be reached because none was recovered from these particular animals. The recovery of ureaplasmas and mycoplasmas from the vagina of so many of the animals made it clear that it would not be easy to associate these organisms with reproductive failure and quantitative assessments indicated that there was no association. However, we have only been able to look for organisms in the lower genital tract and so our findings do not exclude the possibility that those in the upper tract, assuming they sometimes reach this site, might affect reproduction. Two further approaches are clearly pertinent. The first would involve an attempt to isolate micro-organisms, not only ureaplasmas and mycoplasmas, from the endometrium by using a procedure that avoids contamination from the lower genital tract. The second approach, dependent on the first, would be to administer antibiotics, tetracyclines or erythromycin, to those animals with a poor reproductive performance that were found to be infected in the upper tract and determine whether there was an improvement.

We thank Marc Murray and Paul Gonzales (Primate Research Institute) and Marion Grabowski (Mycoplasma Laboratory, Center for Drugs and Biologics) for their help in this study.

\section{References}

Brown, W.J., Jacobs, N.F., Arum, E.S. \& Arko, R.J. (1976) T-strain mycoplasma in the chimpanzee. Lab. Anim. Sci. 26, 81-83.

Clyde, W.A. (1964) Mycoplasma species identification based upon growth inhibition by specific antisera. $J$. Immunol. 92, 958-965.

Cole, B.C., Graham, C.E. \& Ward, J.R. (1970) The isolation of mycoplasmas from chimpanzees. In The Chimpanzee, Vol. 2, pp. 390-409. Ed. G. H. Bourne. Karger, Basel.
Furr, P.M. \& Taylor-Robinson, D. (1987) Prevalence and significance of Mycoplasma hominis and Ureaplasma urealyticum in the urines of a non-venereal disease population. Epidem. Inf. (in press).

Furr, P.M., Taylor-Robinson, D. \& Hetherington, C.M. (1976) The occurrence of ureaplasmas in marmosets. Lab. Anim. 10, 393-398.

Khatamee, M.A. (1982) Mycoplasma colonization in primate animal laboratories. Int. J. Gynaecol. Obstet. 20, 245-249. 
Manchee, R.J. \& Taylor-Robinson, D. (1968) Haemadsorption and haemagglutination by mycoplasmas. $J$. gen. Microbiol. 50, 465-478.

Mårdh, P.-A. (1986) Ascending chlamydial infection in the female genital tract. In Chlamydial Infections, pp. 173-184. Eds D. Oriel, G. Ridgway, J. Schachter, D. Taylor-Robinson \& M. Ward. Cambridge University Press.

Mouches, C., Taylor-Robinson, D., Stripkovits, L. \& Bove, J.M. (1981) Comparison of human and animal ureaplasmas by one- and two-dimensional protein analysis on polyacrylamide slab gel. Annls Microbiol. (Inst. Pasteur) 132B, 171-196.

Swenson, C.E. \& O'Leary, W.M. (1977) Genital ureaplasmas in nonhuman primates. J. med. Primat. 6, $344-348$.

Taylor-Robinson, D. (1986) The male reservoir of Ureaplasma unrealyticum. Pediatr. Infect. Dis. 5, Suppl., 335-337.

Taylor-Robinson, D. \& Gourlay, R.N. (1984) Ureaplasma. In Bergey's Manual of Systematic Bacteriology, vol. 1, pp. 770-775. Ed. N. R. Krieg. Williams and Wilkins, Baltimore.
Taylor-Robinson, D. \& McCormack, W.M. (1980) The genital mycoplasmas. N. Engl. J. Med. 302, 1003-1010 and 1063-1067.

Taylor-Robinson, D. \& Purcell, R.H. (1986) Mycoplasmas of the human urogenital tract and oropharynx and their possible role in disease: a review with some recent observations. Proc. roy. Soc. Med. 59, 1112-1116.

Taylor-Robinson, D., Martin-Bourgon, C., Watanabe, T. \& Addey, J.P. (1971) Isolation of T-mycoplasmas from dogs and squirrel monkeys: biological and serological comparison with those isolated from man and cattle. J. gen. Microbiol. 68, 97-107.

Thomas, B.J., Evans, R.T., Hutchinson, G.R. \& TaylorRobinson, D. (1977) Early detection of chlamydial inclusions combining the use of cycloheximidetreated McCoy cells and immunofluorescence staining. J. clin. Microbiol. 6, 285-292.

Received 21 January 1987 